American Journal of Pharmaceutical Education 2018; 82 (7) Article 6806.

\title{
COMMENTARY
}

\section{Reflections on the Pharmacist-Patient Covenant}

\author{
Amy M. Haddad, PhD \\ Creighton University School of Pharmacy and Health Professions, Omaha, Nebraska \\ Submitted September 21, 2017; accepted September 25, 2017; published September 2018.
}

\begin{abstract}
The first tenet of the Code of Ethics for Pharmacists of the American Pharmacists Association describes the relationship between the pharmacist and the patient as a covenant. The central argument of this commentary is that the symbolic language of covenant, the metaphor used to describe the pharmacistpatient relationship, should be formally acknowledged as an ideal theory or concept. However, before committing to this ideal, there should be resonance with the realities of pharmacy practice. This commentary argues that the intimate nature of a covenantal relationship is not a good fit with most contexts in which pharmacists practice. The disconnection between the ideal of the covenantal relationship and context is important because codes of ethics apply regardless of context. By acknowledging the ideal of a covenantal relationship, transitional structures could then be developed to move the pharmacy profession toward this ideal.
\end{abstract}

Keywords: covenant, code, ethics, pharmacist-patient relationship

\section{INTRODUCTION}

The pharmacist-patient relationship has changed over the past 30 years from one in which pharmacists focused solely on filling prescriptions without questioning a physician's order to one in which pharmacists recommend drug therapy to prescribers and offer personalized advice to patients on how to maximize the benefits of their medication. A revision in the Code of Ethics for Pharmacists of the American Pharmacists Association was adopted in 1995 and reflects this change in the nature of the pharmacist-patient relationship. The Code's primary purposes described in the preamble are to "state publicly the principles that form the fundamental basis of the roles and responsibilities of pharmacists" and to "guide pharmacists in relationships with patients." The first purpose is important because any declaration by a profession establishes public expectations. The second purpose is even more important because the nature of the relationship shapes, consciously or unconsciously, the identity of every pharmacist.

In the first tenet of the Code, the relationship of the pharmacist and patient is described as a covenant - "A pharmacist respects the covenantal relationship between the patient and the pharmacist."1 The symbolic language of covenant should be formally acknowledged as an ideal theory or concept so transitional structures could be

Corresponding Author: Amy M. Haddad, Department of Pharmacy Sciences, Creighton University School of Pharmacy and Health Professions, 2500 California Plaza, Omaha, NE 68178. Tel: 402-280-2164. E-mail: ahaddad@creighton.edu developed to move the pharmacy profession toward the ideal covenantal relationship. However, before committing to this ideal, the realities of pharmacy practice should resonate. The intimate nature of a covenantal relationship is not a good fit with most contexts in which pharmacists practice. This disconnection between the ideal covenantal relationship and context is important because codes apply regardless of context. The International Federation of Pharmacist's Statement of Professional Standards Codes of Ethics for Pharmacists doesn't provide any information about the nature of the relationship between patient and pharmacist but states, "The code of ethics will therefore apply to pharmacists in all practice settings."2

Why is this type of reflection on the nature of the relationship to the patient important to the profession of pharmacy? This commentary will offer two reasons. The first has to do with the basic purpose of pharmacy, which is to "optimize medication use and improve patient health." The assumption is that the purpose of pharmacy is achieved through the establishment of a pharmacist-patient relationship. It is the process or means whereby pharmacists carry out the purpose of pharmacy. It is important to be clear about the nature of this relationship. As Zlatic notes, "Nomenclature sets up paradigms that govern our thinking, actions and structures." In fact, the words we use to describe the relationship create reality and responsibilities, which leads to the second reason that a reflection of this type is important. Because "covenant" is the foundation, touchstone or bedrock for the pharmacist-patient relationship, the concept creates obligations, helps identify where those obligations begin and end, and requires 


\section{American Journal of Pharmaceutical Education 2018; 82 (7) Article 6806.}

certain actions to fulfill such obligations. There are numerous conceptual models to describe the relationship between patients and health professionals. Exploring alternative models can offer insights into how the relationship and expectations of those involved differ.

The commentary will proceed in four stages. First, it will briefly sketch the history of the concept of covenant to describe the health professional-patient relationship in general and pharmacy. Then it will consider the largely unquestioned adoption of covenant as the foundation of the relationship between pharmacist and patient, what it requires of pharmacist and patient in "ideal" terms and contrast it with other types of relationships such as "fiduciary" or "contractual" and why that matters. Third, it will reflect on the impact and influence of context on the ideal relationship between pharmacist and patient using the context of community pharmacy and note the barriers to the covenantal concept. Finally, it proposes ways to work toward transitional structures to the ideal of covenant as well as alternate conceptualizations of the patient-pharmacist relationship.

\section{Preludes to the Adoption of Covenant as Foundation for Pharmaceutical Care}

The introduction of the concept of covenant in pharmacy starts with the seminal work of Hepler and Strand in 1990. ${ }^{5}$ Prior to that, covenant, as applied to health care, can be traced to two theologians, Paul Ramsey and William F. May. Ramsey noted in his foundational work, "The Patient as Person," in 1970 that "canons of loyalty (such as the pharmacist-patient relationship) are particular manifestations of canons of loyalty of person to person generally." 6 Ramsey then uses the term covenant, a term with biblical roots, stating: "We are born within covenants of life with life" and finally asks "What is the meaning of faithfulness of one human being to another in every one of these relations?"6

May focused this general call to health professionals to be faithful in their relationships with patients to the specific relationships involving physicians. In an oft-cited article, May contrasted a variety of foundational concepts for such relationships including code, covenant, contract and philanthropy. ${ }^{7}$ May drew a distinction between a professional code and a covenant. Codes are more focused than covenant on shaping behavior through habits and rules of a profession. For example, one should do this, one should not do that. He argues that codes do not "encourage personal involvement with the patient." Covenants, on the other hand, are more internal-oriented. A covenant includes the following elements: " 1 ) an original experience of gift between the soon-to-be covenanted partners; 2) a covenantal promise based on this original or anticipated exchange of gifts, labors or services; and 3 ) the shaping of subsequent life for each partner by the promissory event." 7 There is a reciprocal sense of indebtedness that helps level the inequities within the relationship (ie, the neediness of patients vs the expertise and self-sufficiency of health professionals). If we apply this concept to pharmacy, some of the elements could apply to the pharmacist-patient relationship. It is clear why patients need pharmacists. It is harder to see why pharmacists need patients. Pharmacists need patients to be pharmacists. Pharmacists learn from patients what it means to be ill, injured, or dependent on medication to survive. The pharmacist is obligated to fulfill the requirements of the covenant regardless if the terms of the relationship are made explicit. ${ }^{8}$

A third type of relationship that May explores is a social contract that is external to the person and is closer to the elements of informed consent than just putting blind trust into a health professional. May is generally not in favor of a social contract model for health professionalpatient relationships, but the model has merits that are worth exploring by the pharmacy profession. Social contracts contain components that respect the dignity of those involved. There is an exchange of information and an agreement is reached that includes rights, duties, conditions and qualifications. ${ }^{7}$ There is legal recourse if something goes wrong. A contract model presupposes that there is self-interest on both sides and so a good contract works to the individual advantage of the parties involved. On the downside, contracts reduce any obligations outside of the stated agreement, which can lead to minimalism on the part of the health professional. Since health care is unpredictable, patients would likely be in favor of less stringency in what the health professional will and will not do. Contracts could also lead to defensive practice by following the letter of the law and no more.

A distinction should be made between a covenantal relationship and a fiduciary one. There is considerable muddling of the terms "fiduciary" and "covenantal" in the pharmacy literature. A fiduciary relationship has legal and business implications. In a fiduciary relationship, "one person places complete confidence in another in regard to a particular transaction or one's general affairs or business. The relationship is not necessarily formally or legally established as in a declaration of trust, but can be one of moral or personal responsibility, due to the superior knowledge and training of the fiduciary as compared to the one whose affairs the fiduciary is handling."9 There is no mention of an exchange of gifts or mutual benefit. Those with superior knowledge in such relationships have the upper hand and thus bear the obligation to respect the trust placed in them. 


\section{American Journal of Pharmaceutical Education 2018; 82 (7) Article 6806.}

Hepler and Strand relied on May's work in their definition of pharmaceutical care and a few years later, the concept appears in the revised Code of Ethics for Pharmacists. There is no direct or indirect statement as to whether the covenantal relationship is an ideal to which the profession of pharmacy should aspire or a confirmation of fact. The Code of Ethics reads as if affirming the present state that requires pharmacists to respect the "covenantal nature" of the relationship. ${ }^{1}$ One of the few places in the pharmacy literature where this ideal vs. real distinction is addressed is in the textbook "Ethical Responsibility in Pharmacy Practice," where the authors express the hope that the Code and concept of pharmaceutical care "may bring the profession of pharmacy closer to this ideal." 10

In other words, there is a lack of clarity regarding the concept of covenant. Furthermore, members of the pharmacy profession should know whether they are aspiring to an ideal or not. Second, if covenant is an ideal, it should still be grounded in the lived experience of those who must carry out professional duties within this ideal relationship.

\section{Acceptance of the Covenantal Concept as the Foun- dation of the Pharmacist-Patient Relationship}

There is considerable evidence that the covenantal relationship has been uniformly adopted in textbooks, classrooms and clinical settings in pharmacy education and practice. References to the covenantal relationship are everywhere in the pharmacy literature especially in the areas of professionalism and ethics. For example, almost any reference to the Code of Ethics includes a reminder that the Code "stresses covenantal relationship with patients" 11 while others include it in the very definition of professionalism as in "the goal of professionalization is to develop the characteristics of being a professional (ie, technical knowledge, accountability, covenantal relationships, etc.)." ${ }^{\prime 2}$ Some go so far as to say "the covenantal relationship is the essence of all professional relationships..."13 Still others place the covenantal relationship as the hub of professional activities of the pharmacist stating, "If one lacks the core value of the covenantal relationship then all other professional behaviors will lack strength and substance." 14

There are often references in the pharmacy literature to the Code of Ethics as a source for guidance in the resolution of a practical ethical or professional problem and thereby the ideal of the covenant is also applied. There are many examples in the pharmacy educational literature where students are asked to apply the Code of Ethics to a case or scenario and reason to what course of action should be taken. ${ }^{15,16}$
Despite the number of references to the covenantal concept, there is a paucity of reflection, criticism or questioning in the pharmacy literature on the appropriateness of this ideal concept for pharmacy. Is it prescriptive or descriptive? Fitting or frustrating? It is important to recall here that a key requirement of a code and the conceptual framework on which it is built is that it must apply to all pharmacists in all practice settings. Thus, let us turn to the context of the pharmacist-patient relationship to explore these questions of general applicability and fit.

\section{Impact and Influence of Context on Relationship}

Pharmaceutical care grew out of academic medical centers and academic pharmacy, so it follows that the covenantal concept would fit best in this practice setting as it would in free-standing pharmacies that focus on medication therapy management (MTM). The context in which pharmacists are best equipped to provide MTM brings us closer to realizing covenant because there is access to broader and consistent information about the patient's health status that extends beyond medications, the opportunity for multiple interactions with the team to gain more knowledge about aspects of a patient's life that will have implications for MTM, and time to build trust. However, most pharmacists practice in community settings. What does the pharmacist-patient relationship look like in the community pharmacy setting? Consider a standard pharmacy ethics case describing an interaction in a community pharmacy between a pharmacist and a patient:

Mary Phillips, PharmD, prided herself on her ability to keep in touch with her patients. Dr. Phillips had known Cora Jackson for many years. Mrs. Jackson picked up the prescriptions for herself and her husband, Jake, on a regular basis. Dr. Phillips noticed that this past month, Mrs. Jackson asked for the refill only of her husband's antihypertensive drug, furosemide. Dr. Phillips asked Mrs. Jackson if her prescription for chlorthalidone had been discontinued or changed by Mrs. Jackson's physician. The patient replied, "Oh no, I haven't been to see Dr. Williams. We, that is Jake and I, just decided to cut some corners. You know how expensive these drugs are, especially mine. So, we decided to just get one blood pressure prescription filled, and we'd share. Jake's was less expensive, and one pill is as good as another. I just split the pills in half. We don't have enough money to get both prescriptions filled and still pay the heating bills."

Dr. Phillips knew that her own heating bills had risen substantially in the subzero weather. She also knew that Mr. and Mrs. Jackson were on a fixed income. Dr. Phillips felt that she should try and persuade Mrs. Jackson to give higher priority to health. As a pharmacist, she also knew that splitting pills in half was not appropriate and would 


\section{American Journal of Pharmaceutical Education 2018; 82 (7) Article 6806.}

probably not do any more good than not taking any medication at all. Yet, Dr. Phillips recognized that the health and comfort of Mr. and Mrs. Jackson depended on adequate heating. ${ }^{17}$

Chambers argues that "Stories of moral dilemmas, like all narratives, are constructed from a specific point of view, which persuades us to see the events in a particular manner." "Consider the various aspects of the case that frame the nature of the relationship of the patient and the pharmacist. In this instance, the point of view of the case is the pharmacist's. We see the world through Mary Phillip's eyes and she is someone who "takes pride" in keeping in touch with her patients. She knows things about them and their lives that can and do have an impact on their MTM. She knows their drug history; she notices a change and asks about it. Mrs. Jackson trusts Dr. Phillips enough to tell her about their scheme to save needed money and why. Dr. Phillips is concerned about this risky plan and begins to weigh the benefits and harms in the situation, a clinical and ethical calculus. Dr. Phillips might or might not be prompted by the patient's history in the pharmacy's computer to ask about Mr. Jackson's refill, but it is the trusting relationship that has already been established that causes Mrs. Jackson to answer candidly. Most of the elements of a covenantal relationship are here. The exchange of gifts of trust and confidence from the patient and in return the competence and care from the pharmacist. The case affirms through its choice of words and "back story" that Mary Phillips is a "good" pharmacist who cares enough about her patients to get to know them, maintain an open and trusting relationship over time, takes time, a precious commodity, to talk to them when they are in the pharmacy and asks questions that are specific to the needs of this patient now. She also understands about the high cost of heating bills as she too must pay more to heat her own home. This understanding speaks to mutuality. This case is a good example of how perspective and voice affect the reader's vision of the pharmacist-patient relationship.

In contrast, the real world of community pharmacy practice is different in several ways from the one in which Dr. Phillips and Mrs. Jackson engage. Real community pharmacies are full of barriers to the ideal of covenant such as lack of consistent and complete patient information, lack of patient understanding of the expertise of the pharmacist, and lack of privacy and time for exchange of personal and professional information. It is also confusing in a community setting as to which obligations take priority when there are conflicting duties to one's employer and prescribers. Patients often don't make this any clearer or easier in that they often use several pharmacies and see multiple physicians. Pharmacists must also deal with a variety of payers and regulations. Pharmacists spend considerable time navigating these multiple barriers to get the right drug to the right patient with appropriate payer approval. Is there any way, given these structural constraints for pharmacists to know patients well enough for the ideal in which patients "exchange the gifts of information about their health with the expertise of the pharmacist"?

The next ethics case regarding a common interaction between a patient and pharmacist highlights the challenges to the development of a covenantal relationship in community pharmacy practice.

Dan Mac, PharmD, the manager of a community pharmacy, sighed when Nancy Roeggenbach handed him a manufacturer's "coupon" for a $\$ 4$ co-pay for Drug $X$. Right away he knew that filling Ms. Roeggenbach's prescription would take more time in an already busy day and that this new prescription would cost her more. The small print on the back of the card confirmed the way it worked: Dr. Mac would run the prescription through Ms. Roeggenbach's insurance to find out how much her cost would be, then he would run it through with the coupon code, which should take $\$ 126$ off her $\$ 130$ copay. Dr. Mac had seen this before; most insurance plans did not cover brand-name Drug X, and it was going to cost Ms. Roeggenbach more than the stated $\$ 4$ co-pay if she wanted it today.

Ms. Roeggenbach had been taking delayed-release diclofenac and was doing well on that regimen when he last spoke to her. Delayed-release diclofenac was on the pharmacy's $\$ 4$ list, so she was only paying $\$ 4$ per month for her medication now. He wondered why there had been a change to Drug X. Dr. Mac now had to submit a claim to her insurer and another one to the drug manufacturer.

As he ran the prescription for Ms. Roeggenbach through the computer, Dr. Mac saw that despite the advertised $\$ 4$ co-pay, her cost was going to be over $\$ 450$ if she wanted it today. This was a great deal more than $\$ 4$. Her insurance required preapproval because of the availability of generics. ${ }^{17}$

Dr. Mac is faced with opposing obligations here to the patient, the prescriber, the pharmacy, the manufacturer, and the insurer. The context and facts of the case place Dr. Mac in a situation where it is difficult to discern what it means to do what is best for this patient. In this case, the pharmacist knows the patient somewhat, but doesn't know why the drug has been changed. He might assume that the patient thought she was getting a newer, better drug for no more than what she had been paying. Maybe she found a coupon online or a friend told her about the drug or she saw an ad on television. We also don't know why the physician changed the prescription or 


\section{American Journal of Pharmaceutical Education 2018; 82 (7) Article 6806.}

if he or she knows anything about the cost of the drug, coupons, or any of this complicated structure to shift patients to newer, more expensive products. Clearly it is more work for the pharmacist which takes time away from other beneficial activities and creates greater distance between the pharmacist and the patient.

As we move to other settings in which pharmacists practice, we can start to see how the concept of covenant is further stressed or stretched when context is considered. For example, specialty pharmacies and other types of settings include interactions that often occur at a distance with patients and prescribers. What sort of compensatory skills must a pharmacist possess for the lack of face-toface interaction to build trust and establish relationships? In some of these settings, the need for a trust-based relationship is perhaps higher given that specialty pharmacies, for example, were developed to deliver generally expensive, difficult to administer drugs or drugs with serious side effects and adherence problems.

\section{Possible Ways to Work Toward a Clearer Understanding of the Pharmacist-Patient Relationship}

One needs the ideal theory so one has a clear vision of what the ideal outcome should look like. In other words, the ideal should have "logical priority" but not "temporal priority." If the pharmacy profession hopes to reach the ideal of the covenantal relationship over the long term, then the profession should focus first on recognizing and evaluating changes that may be achievable under the current contextual realities of pharmacy practice. ${ }^{19}$ To that end, we can turn to non-ideal theory that envisions mechanisms for moving pharmacists and their clinical circumstances toward a practice environment and structures characteristic of the ideal of a covenantal relationship. Think about the ideal theory or concept as the peak of a very tall mountain and the non-ideal theory as the base camps placed strategically up the mountain. In that manner, the mountain climbers can measure their progress toward their goal of attaining the summit. Also, they have a place to return to if the distance between camps is too far. Another aspect of this metaphor is that you should be as certain as you can that this is the mountain you want to climb.

Briefly, here are some ideas for transitional mechanisms that could support the move toward the ideal model. Any work of this type should be undertaken by representatives of the profession from a broad array of pharmacy settings. Additionally, the involvement of students and patients, perhaps patients who commonly use the services of specialty pharmacies, in such an endeavor would shed some light from those entering the profession and recipients of pharmaceutical care. Such a task force or blue-ribbon panel could start by launching an effort to identify the concrete features of the actual relationship of the pharmacist and patient in representative settings. This would allow us to see commonalities. Such data would help determine the gap between the ideal and the real. Perhaps a set of fundamental obligations could be established as the basis for the relationship that grows more complex with the involvement of the pharmacist in direct patient care (ie, more will be expected of the pharmacist in relationship with the patient as the stakes escalate). Finally, changes to the structural environment in which pharmacists work and its impact on movement toward the ideal relationship should be explored. As Dikun and colleagues note, pharmacy should consider "the importance of the pharmacists' environment to the successful provision of advanced patient case. This lack of attention to the work environment may stem from 'individual blame bias' wherein all the responsibility for not providing advanced patient care falls on pharmacists, rather than on the system of which they are a part. $" 20$

A totally different approach is for the profession to choose another mountain to climb and explore alternative ideal theories or conceptual models for the relationship such as a social contract as previously described by May or a therapeutic alliance that inspires trust, encourages open communication, and values the patient as an equal partner in therapeutic decisions. ${ }^{21}$ The pharmacist's role could also be envisioned as a mediator, protector, or advocate all rich metaphors that offer promising alternatives to describe the complex nature of the patient-pharmacist relationship.

\section{REFERENCES}

1. American Pharmaceutical Association. Code of ethics for pharmacists. 1995. The organization changed its name to the American Pharmacists Association in 2003 but retains this code of ethics.

2. International Pharmaceutical Federation. FIP statement of professional standards - codes of ethics for pharmacists. Approved by FIP Council in August 2014; http://www.fip.org/www/uploads/ database_file.php?id=351\&table_id=. Accessed March 24, 2017. 3. American Pharmacists Association. Vision and mission for pharmacy. 2011. www.pharmacist.com/vision-and-missionpharmacy-profession. Accessed March 10, 2017

4. Zlatic TD. Mixing metaphors in pharmacy education is a bad solution for students. Am J Pharm Educ. 2014;78(10):Article 175. 5. Hepler CD, Strand LM. Opportunities and responsibilities in pharmaceutical care. Am J Hosp Pharm. 1990;47(3):533-543. 6. Ramsey P. The Patient as Person. New Haven, CT: Yale University Press; 1970:xii.

7. May WF. Doe, covenant, contract and philanthropy. In: The Hasting Center Report. 1975;5(6):29-38.

8. Cooper MC. Covenantal relationships: grounding for the nursing ethic. ANS Adv Nurs Sci. 1988;10(4):48-59. 


\section{American Journal of Pharmaceutical Education 2018; 82 (7) Article 6806.}

9. Fiduciary relationship. http://dictionary.law.com/Default.aspx? selected =745. Accessed March 10, 2017.

10. Buerki RA, Vottero LD. Ethical Responsibility in Pharmacy Practice. Madison, WI: American Institute of the History of Pharmacy; 1994:67.

11. Schlesselman LS. A cross-sectional study of applied bioethical reasoning in pharmacy students and proctors. Pharm Pract. 2014; 12(2):401.

12. Khanfer NM, Zapantis A, Alkhateeb FM, Clauson KA, Beckey C. Patient attitude toward community pharmacist attire. J Pharm Prac. 2012;26(4):442-447.

13. Lee C, Segal R, Kimberlin C, Smith WT, Weiler RM. Reliability and validity for the measurement of moral disengagement in pharmacists. Res Social Adm Pharm. 2014; 10(2):297-312.

14. Motycka C, Williams JS, Hogan T, Gray M, Hartman J. The challenges of professional development in the evolving world of pharmacy education. J Curric Teach. 2014;3(1).
15. Kelling SE, Aultman JM. Promotion of ethical principles in provision of medication therapy management. Innov Pharm. 2014;5(1):Article 143.

16. Smith MG, Dinkins MM. Early introduction to professional and ethical dilemmas in a pharmaceutical care laboratory course. $\mathrm{Am} \mathrm{J}$ Pharm Educ. 2015;79(10):Article 156.

17. Veatch R, Haddad A, Last EJ. Case Studies in Pharmacy Ethics. $3^{\text {rd }}$ ed. New York, NY: Oxford University Press; 2017.

18. Chambers T. The Fiction of Bioethics. New York, NY: Routledge; 1999:21.

19. Hendrix BA. Where should we expect social change in non-ideal theory. Political Theory 2013;41(1):116-143.

20. Dikun JA, Crumby AS, Shahpurwala Z, Hall J, Charrois TL, Rosenthal MM. Understanding pharmacist success in practice: a scoping review. Am J Pharm Assoc. 2016;56(6):649-655. 21. Mey A, Knox K, Kelly F, et al. Trust and safe spaces: mental health consumers' and carers' relationship with community pharmacy staff. Patient. 2013;6(4):281-289. 